\title{
Mercury in vaccines: A review
}

\author{
Shambhawi Roy ${ }^{1}$, Anju Aggarwal ${ }^{2}$, Gayatri Dhangar ${ }^{1}$ and Atul Aneja ${ }^{1}$ \\ ${ }^{1}$ Senior Resident, Department of Pediatrics, University College of Medical Sciences and Guru, Tegh Bahadur Hospital, New Delhi, India \\ ${ }^{2}$ Professor, Department of Pediatrics, University College of Medical Sciences and Guru, Tegh Bahadur Hospital, New Delhi, India
}

\begin{abstract}
Introduction: Mercury in the form of thiomersal has been used as a preservative in vaccines since 1930s. The association of autism and other neurological deficits following mercury exposure through vaccine administration is a doubt which haunts many parents.

Material and methods: A search of medical literature was carried out on Pubmed/MEDLINE and relevant publications on this topic were included.

Results: The forms of mercury, its metabolism and the history of thiomersal use in vaccines was traced through various studies. Published literature citing both positive and negative association between thiomersal exposure and occurrence of neuro-developmental disorders was reviewed.

Conclusion: It is not possible to prove that thiomersal is completely safe. Need of the hour is to eliminate or reduce this preservative in the background of the debate surrounding its safety. At the same time the risk associated with not immunizing a child against preventable diseases greatly outweighs the unfounded risk associated with mercury toxicity from the vaccines.
\end{abstract}

\section{Introduction}

Mercury is a ubiquitous element in our environment. An organomercurial derivative Thiomersal (49.55\% $\mathrm{Hg}$ by weight) has been used as a preservative in vaccines and immunoglobulin preparations [1]. It has been hypothesized that early exposure to this compound is associated with neuropsychological deficits in children [2]. Numerous studies have been published with conflicting results regarding the role of mercury in causing such neurological defects in children. The present article is an attempt to review the literature with regard to the controversy surrounding the use of thiomersal in vaccines and its effects on neuro-developmental outcomes in children.

\section{Materials and methods}

We performed a MEDLINE/Pubmed search for articles on mercury containing vaccines in the literature in English. The following key words were used: a) mercury and vaccines, b) mercury exposure and early life, c) neurodevelopment and thiomersal exposure. We included the relevant published studies that had information on forms of mercury, its metabolism, thiomersal content of vaccines and effects of mercury exposure on neuro-developmental outcome in children.

\section{Results}

Forms of mercury, its metabolism and thiomersal use in vaccines

Mercury is a metal which is liquid at room temperature. The chemical symbol, Hg, is derived from "hydrargyros," the Greek for "water silver". Mercury has a long and interesting history deriving from its use in medicine and industry, with the resultant toxicity produced. Basic forms of mercury are Organic and Inorganic. Organic form further can be classified as rapidly degradable type (e.g. Phenyl $\mathrm{Hg}$ ) and relatively stable type (e.g. Methyl $\mathrm{Hg}$ and Ethyl $\mathrm{Hg}$ ). Today the most widespread human exposures are to mercury vapor emitted from amalgam tooth fillings, to ethylmercury as a preservative in vaccines, and to methylmercury in edible tissues of fish. These molecules are mobile within the body and exhibit a high potential to damage the brain [3].

Although these molecules (methylHg and ethylHg) differ by only one carbon atom, the difference isn't trivial. Ethylmercury is excreted from the body much more quickly than methylmercury and is therefore much less likely to accumulate. Methylmercury is the predominant form of organic mercury found in the environment. Consumption of fish is the primary route of exposure to organic mercury for children older than 1 year. The top 10 commercial fish species which represent about $85 \%$ of the seafood market, contain a mean mercury level of approximately $0.1 \mu \mathrm{g} / \mathrm{g}$ [4]. Ethylmercury is much more rapidly cleared from the blood, with a half-life of 7 to 10 days; therefore, the accumulation of Ethylmercury within the body would not be expected when exposures are intermittent and separated by a time period greater than 1 to 2 months, as seen with immunization administration [5]. Ethylmercury is metabolized much more quickly to divalent $\mathrm{Hg}^{++}$than Methylmercury [6]. The human brain seems particularly vulnerable to methyl mercury during its developmental period due to the chemical's highly and selectively toxic effects on the central nervous system. The prenatal period is believed to be the most susceptible stage of the life cycle. Mercury inhibits processes basic to brain development such as neuronal cell division and migration [7].

Correspondence to: Anju Aggarwal, Professor, Department of Pediatrics, University College of Medical Sciences and Guru, Tegh Bahadur Hospital, New Delhi-110058, India, Tel: 9910329791; E-mail: aanju67@gmail.com

Key words: mercury related neurodevelopmental disorders, mercury and autism thiomersal safety in vaccines

Received: October 22, 2016; Accepted: November 21, 2016; Published: November 24, 2016 
Thiomersal is an organic mercury-containing compound that is $49.55 \%$ mercury $(\mathrm{Hg})$ by weight, and initially metabolized to ethylmercury compounds and thiosalicylate. Thiomersal is effective as a preservative in concentrations of $0.001 \%$ ( 1 part in 100,000$)$ to $0.01 \%$ ( 1 part in 10,000 ). If a vaccine has a $0.01 \%$ concentration of thiomersal, it means that it contains 50 micrograms of thiomersal per $0.5 \mathrm{ml}$ dose or 25 micrograms of mercury per $0.5 \mathrm{ml}$ dose [8]. Thiomersal rapidly dissociates into ethyl-Hg chloride, ethyl-Hg hydroxide and sodium thiosalicylate in saline solutions, and the resulting ethyl-Hg species have high affinities for being bound to free thiols in living systems [9]. It is then actively transported across the blood brain barrier, including by the L-type neutral amino acid carrier transport (LAT) system, into human neuronal cells $[10,11]$, where it significantly accumulates and persists for many months following exposure and alters numbers of neurons in the dentate gyrus of the hippocampus and thalamus [12, 13].

Various agencies have developed guidelines for safe exposure to methylmercury, including the U.S. Environmental Protection Agency, U.S. Agency for Toxic Substances and Disease Registry, the FDA and the World Health Organization. These exposure levels range from 0.1 $\mu \mathrm{g} / \mathrm{kg}$ body weight/day (EPA) to $0.47 \mu \mathrm{g} / \mathrm{kg}$ body weight/day (WHO) [14]. However, it must be noted that all these guidelines are based on studies done on methylmercury and thiomersal leads to ethylmercury exposure. Being different chemical entities these have varying toxicity profiles. Lack of definitive data on ethylmercury toxicity led the FDA to consider ethyl and Methylmercury as equivalent in its risk evaluation [15].

Thiomersal has been used as a preservative in vaccines since the 1930s as it is very effective in killing bacteria in vaccines and in preventing bacterial contamination especially multidose containers. The antibacterial activity of thiomersal is attributed to the ethyl mercury cation that dissociates from the thiomersal molecule [16].

Before 1999, there was $25 \mu \mathrm{g}$ of mercury in each $0.5-\mathrm{ml}$ dose of most diphtheria and tetanus toxoid and acellular pertussis vaccines as well as some Haemophilus influenza type b, influenza, meningococcal, pneumococcal, and rabies vaccines. In addition, there was $12.5 \mu \mathrm{g}$ of mercury in each dose of the hepatitis $B$ vaccine. The reference doses established by federal agencies were between 0.1 and $0.4 \mu \mathrm{g} / \mathrm{kg} / \mathrm{d}$ [17]. Thus a single vaccination could potentially exceed federal guidelines for that day and, with routine immunization, a cumulative dose of up to $75 \mu \mathrm{g}$ of mercury by 3 months of age and $187.5 \mu \mathrm{g}$ by 6 months of age could have been received. This had led to the suggestion that childhood vaccination with thiomersal containing vaccines increases the risk of neurodevelopmental disorders, such as autism, attention-deficit/ hyperactivity disorder, and language and speech delay [18].

The American Academy of Pediatrics and the US Public Health Service in 1999 published a joint statement that urged "all government agencies to work rapidly toward reducing children's exposure to mercury from all sources." The statement recommended that thiomersal be removed from vaccines as soon as possible as part of this overall process [19].

Following this, in developed countries, thiomersal has been removed from or reduced to trace amounts in all vaccines routinely recommended for children 6 years of age and younger, with the exception of inactivated influenza vaccine. Updated list of vaccines and their thiomersal content has been released by the FDA (15). In India, presently, certain brands of Hepatitis B vaccine (Genevac B), DTwP vaccine combinations (Pentavac) and inactivated influenza vaccines
(Multidose Vaxigrip) contain Thiomersal as preservative ranging from $0.005 \%$ in Hep B and DTwP vaccines to trace $(1 \mu \mathrm{g} / 0.25 \mathrm{ml}$ dose $)$ in influenza vaccine [20].

\section{Studies}

Positive evidence: In light of the apparently increased incidence of autism in the 1990s, along with the increased mercury exposure through the childhood vaccination program in the United States, the hypothesis of thiomersal-containing vaccines as an etiology for autism seemed plausible to some, but anecdotal to others [21]. It is important to note that the National Research Council of the US National Academy of Science in 2000 determined that there is a causal relationship between childhood methylmercury exposure and neurodevelopmental disorders [22].

As per results of an ecological study it was observed that there were significantly increased rate ratios for the neurodevelopmental disorders of autism, autistic spectrum disorder (ASD), hyperkinetic syndrome of childhood (attention deficit disorder/attention deficit hyperactivity disorder), developmental disorder/learning disordernot otherwise specified, disturbance of emotions specific to childhood and adolescence, and tics following additional $\mathrm{Hg}$ exposure from thiomersal containing childhood vaccines [23].

Mercury exposure was observed to be significantly associated with neurodevelopmental disorders and autism in a series of epidemiological studies evaluating prenatal/early postnatal environmental $\mathrm{Hg}$ exposure [21,24-26]. A two-phased (hypothesis generating/hypothesis testing) study with documented exposure to varying levels of Thiomersal from vaccinations concluded that there is an association between increasing organic mercury exposure and risk of subsequent autism spectrum disorder (ASD) diagnosis [27]. Several recent brain pathology studies have even revealed elevations in mercury concentrations and mercury-associated oxidative stress markers in patients diagnosed with autistic disorders in comparison with control [24-26]. A case control study was done on dose response relationship between mercury exposure from thiomersal containing vaccines and risk of neurodevelopmental disorders (ND). It reported that the risk of NDs like Pervasive development disorder, specific developmental delay, tic disorder or hyperkinetic syndrome of childhood was more with increasing cumulative total dose of $\mathrm{Hg}$ exposure from thiomersalcontaining childhood vaccines [28]. Similar results were found in another epidemiologic study which evaluated organic $\mathrm{Hg}$ exposure from Thiomersal in Haemophilus influenzae type b (Hib)-containing vaccines administered at specific times within the first 15 months of life and concluded a significantly increased risk of Pervasive development disorders in such children [29]. Increasing Hg exposure from thiomersal in Hepatitis B vaccine administered in first six months of life has been found to be associated with a higher risk of developing hyperkinetic syndrome of childhood as well as developmental delay [30,31].

For a number of reasons, very low birth weight premature infants may be at an increased risk from thiomersal-containing vaccines. One study recommended that thiomersal containing vaccines should not be administered at birth to very low birth weight infants. A study in 2000 measured the exposure of mercury after hepatitis $B$ vaccine in pre term infants. It showed that pre term infants had greater than 10 fold higher mean mercury levels at the base line reading compared with term infants. Preterm infants may not be able to metabolize mercury as well because of immature livers that are not able to synthesize the metal binding protein metallothionein [32]. Another factor that may contribute to higher mercury levels is the reduced body mass of preterm babies. 
A review article has shown evidence of abnormal sulfation chemistry, limited thiol availability, and decreased GSH reserve capacity in children with ASD making them more vulnerable to the toxic effects of thiomersal injected along with vaccines [33]. Other literature reviews have also reported a significant link between ethylmercury exposure from thiomersal in vaccines and neurotoxic effects in humans [1,34].

Negative evidence: A number of studies have also reported lack of any causal relation between thiomersal exposure and occurrence of Autism or other neurodevelopmental disorders. In a population-based cohort study of all children born in Denmark from January 1, 1990, until December 31, $1996(\mathrm{~N}=467450)$ comparing children vaccinated using formulations with or without thiomersal, it was found that there was no evidence of an association between exposure to thiomersal containing vaccine and autism. Furthermore, there was no indication of a dose-response association between autism and the amount of ethylmercury received through thiomersal [18].

In 2004, the Immunization Safety Review Committee reconsidered the possible relationship between autism and thiomersal-containing vaccines. Based on the more recently published epidemiological data, the Institute Of Medicine (IOM) shifted from the position of neutrality to the conclusion that "the evidence favors rejection of a causal relationship between thiomersal-containing vaccines and autism" [35]. Since the 2004 report, two studies from the United Kingdom examining the relationship between thiomersal contained within vaccines and the occurrence of neurodevelopmental disorders have been published; the conclusions reached from both of these studies are in agreement with the 2004 statement of no causal relationship [36,37]. The World Health Organization (WHO) endorses the use of thiomersal containing vaccines for children on the basis that there are no convincing pharmacokinetic or epidemiological studies that have proven thiomersal containing vaccine associated EtHg toxicity $[38,39]$. In addition, the economics of using thiomersal-free vaccines in developing countries may be prohibitive. Therefore, WHO feels that thiomersal-containing vaccine administration is much better than no vaccinations at all in these countries.

There are many biological and epidemiological evidences which support the notion that thiomersal does not cause autism. Some large studies have compared risk of autism in children who received vaccines containing thiomersal to those who received vaccines without thiomersal or vaccines with lesser quantities of thiomersal; the incidence of autism was similar in all groups $[36,37,40]$. The Institute of Medicine has reviewed these studies and concluded that evidence favored rejection of a causal association between vaccines and autism and that autism research should shift away from vaccines [41].

Pichichero and co-workers found that the level of mercury detected in the blood of 40 full-term infants 6 months of age or younger who received thiomersal-containing $\mathrm{DTaP}$, hepatitis $\mathrm{B}$ and Hib vaccines were well within recommended guidelines [16].

Methylmercury is found in low levels in water, infant formula and breast milk. Although, it is clear that large quantities of mercury can damage the nervous system, there is no evidence that the small quantities contained in water, and infant formula and breast milk do. An infant who is exclusively breast-fed for six months will ingest more than twice the quantity of mercury that was ever contained in vaccines and fifteen times the quantity of mercury contained in the influenza vaccine [42].

One known and unfortunate sequel from the uncertainty surrounding the safety of thiomersal was confusion surrounding administration of the birth dose of hepatitis B vaccine. Following the suspension of the routine use of hepatitis B vaccine for low-risk newborns in 1999, there was a marked increase in the number of hospitals that no longer routinely vaccinated all infants at high risk of hepatitis B [43]. As a result, there have been cases of neonatal hepatitis $B$ that could have been prevented, but were not, because of many hospitals suspending their routine neonatal hepatitis B vaccination program.

A comparative pharmacokinetic analysis of mercury levels in infants after yearly influenza vaccine administration (containing thiomersal) was studied in U.S. This study reported that the peak body burden of mercury at 4.5 years of age following yearly exposures to thiomersal did not exceed the corresponding safe body levels of mercury from methylmercury at any time, even for low-birth-weight infants. Thus, supporting the safety of thiomersal when used as a preservative in vaccines [44]. In 2014, a meta analysis of case control and cohort studies concluded that thiomersal in vaccines is not associated with the development of autism spectrum disorders [45].

In Poland, a 9 year prospective birth cohort study was carried out to determine whether cognitive development of children was affected by early exposure to thiomersal containing vaccines (TCV). It included 318 chidren vaccinated against Hepatitis B and DPT in first six months of life using formulations with or without thiomersal. Subsequently, developmental assessment was done periodically till 9 years of age and the results were statistically analysed. It was found that children had similar outcomes of cognitive developmental tests regardless of being exposed to TCVs during early infancy. Thus acknowledging that TCV administration in early life did not affect children's cognitive development [46].

Literature reviews and meta analyses have also rejected the evidence of any causal association between autism and mercury exposure from the preservative thiomersal $[2,45,47]$.

The Global Advisory Committee on Vaccine Safety (GACVS) has stated that they remain of the view that there is no evidence supporting a causal association between neurobehavioral disorders and 'thiomersal' containing vaccines [48].

\section{Discussion}

The public has become intolerant to unnecessary exposure to real and theoretical risks for children from all sources as evidenced by demands to make food products, toys, seat belts, and air bags as safe as possible reducing or eliminating exposure to harmful chemicals from all sources. Further, reduction or elimination of mercury in vaccines will help maintain public confidence by demonstrating a commitment to provide the safest vaccines possible for protecting children against diseases.

Exposure to environmental mercury mainly occurs in its methylmercury form [3]. On the other hand, thiomersal in vaccines dissociates into ethylmercury which is much less toxic as compared to its single carbon atom form [5]. Various guidelines for upper limit of mercury exposure in humans are based on methylmercury and not ethylmercury [14]. These are followed for ethylmercury as well in the absence of relevant data for ethylmercury exposure [15]. Before 1999, numerous vaccines administered to neonates and infants contained thiomersal as preservative. Exposure to mercury in early life was associated with the development of neurodevelopmental disorders and therefore efforts were made to eliminate or decrease the amount of 
thiomersal in vaccines $[18,19]$. However, to date, many vaccines used in developing countries, especially the multidose vials, still contain thiomersal as it is an economical and effective preservative. In India, vaccines against Hepatitis B, DPT and influenza use thiomersal as preservative [20].

It is not possible to prove that thiomersal is completely safe, epidemiology can only quantify a risk, not prove its absence. As for many other vaccine debates, the public demand for a study that shows thiomersal is free of risk, cannot be met. The best epidemiology can do is to indicate the confidence limits to an observation occurring by chance. As discussed earlier, thiomersal exposure has been linked with the diagnosis of Autism, Hyperkinetic syndrome of childhood, Developmental delay and other Neurodevelopmental disorders in several studies [27-31]. Increased vulnerability to this preservative as a result of abnormality of chemical defence mechanisms has been reported in children with ASD [33]. Low birth weight and/or preterm babies are more susceptible to the risk of ethylmercury exposure from TCVs [32].

Thiomersal is a safe preservative to use in vaccines administered to infants, children and non pregnant adults. Many studies have failed to show any association between thiomersal exposure in vaccines and occurrence of Autism or any other neurodevelopmental defects [4447]. On the basis of multiple such studies the Institute of Medicine refuted any evidence of causal relation between TCV exposure and Autism [35]. The WHO has also declared that the use of thiomersal as preservative in vaccines is safe $[38,39]$. Also, the use of thiomersal as a preservative in vaccines is quite feasible in the economically weaker countries due to its low cost and good efficacy. Replacing thiomersal with other cost prohibitive preservatives may decrease immunization coverage in developing countries which in turn might lead to outbreaks of life threatening diseases. Thus, emphasizing that the theoretical risk associated with thiomersal use is better to be taken than the definite risk of vaccine preventable disease outbreak.

The incompletely quantified risk to the fetus, the premature infant and the low birth weight infant suggest it would be better to avoid this preservative in these groups until more data are assembled about its safety in these special groups. Hepatitis B vaccine is one of the preservative containing multidose vaccines to be offered at birth. Eventually, it should be possible to avoid Hepatitis $B$ vaccine preparation that contains thiomersal for the birth dose. This has been achieved in the U.S already by the use of mono dose preparations that are thiomersal free [15]. Developing countries could achieve the same if the birth dose could be a mono dose preparation. Unfortunately, the preparations currently in use in developing countries are generally manufactured with thiomersal, even the mono dose preparations. Changing to a thiomersal free preparation would require expensive re-licensing procedures. To date, the international community has not been sufficiently encouraging towards manufacturers (mostly in developing countries) to switch to thiomersal free lines for part of their production. Efforts should be directed towards making all vaccines free of thiomersal especially those used in early infancy and pregnancy (Hep B, DPT and Influenza).

Certain recommendations by autism advocacy groups [47] regarding avoidance of influenza vaccine have misled parents to place children at risk of potential life threatening diseases. In addition, avoidance of vaccination leads to an unnecessarily increased risk of infections, hospitalization, and death. To ease concerns about mercury toxicity reformulation of vaccines to thiomersal free preparations is warranted but this will involve increased costs associated with vaccine production, increased shipping costs, and increased storage burden. On the basis of the IOM and GACVS report, it can be concluded that there is currently no evidence to support such changes in vaccine formulation for this purpose $[35,48]$.

However, mercury in all of its forms is toxic to the fetus and children, and efforts should be made to reduce exposure to the extent possible to pregnant women and children as well as the general population.

\section{Conclusion}

As a matter of fact, immunization provides immense benefits to public health but certain hazards associated with it are inevitable. Many studies have consistently failed to identify a cause effect relationship between thiomersal exposure and neurobehavioral disorders in children but genuine efforts should be made to reduce or eliminate mercury from vaccines so as to alleviate parental concerns and any doubts about safety of vaccines. Children should receive recommended immunization as per schedule as the risk of known complications from preventable diseases like Hepatitis B, DPT and influenza far outweigh the unfounded risks of adverse consequences from vaccines including TCVs.

\section{Competing interests}

None

\section{Source of funding}

None

\section{References}

1. Geier DA, King PG, Hooker BS, Dorea JG, Kern JK, et al. (2015) Thimerosal: Clinical, epidemiologic and biochemical studies. Clinica Chimica Acta 444: 212-220. [Crossref]

2. Schultz ST (2010) Does thimerosal or other mercury exposure increase the risk for autism? A review of current literature. Acta Neurobiol Exp (Wars) 70: 187-195. [Crossref]

3. Clarkson TW, Magos L (2006) The toxicology of mercury and its chemical compounds. Crit Rev Toxicol 36: 609-662. [Crossref]

4. Goldman LR, Shannon MW (2001) American Academy of Pediatrics: Committee on Environmental Health. Technical report: mercury in the environment: implications for pediatricians. Pediatrics 108: 197-205. [Crossref]

5. Bigham M, Copes R (2005) Thiomersal in vaccines: balancing the risk of adverse effects with the risk of vaccine-preventable disease. Drug Saf 28: 89-101. [Crossref]

6. Bredfeldt JE, Moeller DD (1978) Systemic mercury intoxication following rupture of a Miller-Abbott tube. Am J Gastroenterol 69: 478-480. [Crossref]

7. Clements CJ (2004) The evidence for the safety of thiomersal in newborn and infant vaccines. Vaccine 22: 1854-1861. [Crossref]

8. Tan M, Parkin JE (2000) Route of decomposition of thiomersal (thimerosal). Int $J$ Pharm 208: 23-34. [Crossref]

9. Trümpler S, Meermann B, Nowak S, Buscher W, Karst U, et al. (2014) In vitro study of thimerosal reactions in human whole blood and plasma surrogate samples. J Trace Elem Med Biol 28: 125-130. [Crossref]

10. Wehe CA, Pieper I, Holtkamp M, Thyssen GM, Sperling M, et al. (2014) On-line species-unspecific isotope dilution analysis in the picomolar range reveals the timeand species-depending mercury uptake in human astrocytes. Anal Bioanal Chem 406: 1909-1916. [Crossref]

11. Zimmermann LT, Santos DB, Naime AA, Leal RM, Dorea JG, et al (2013) Comparative study on methyl- and ethylmercury-induced toxicity in C6 glioma cells and the potential role of LAT-1 in mediating mercurial-thiol complexes uptake. Neurotoxicology 38: 1-8. [Crossref]

12. Burbacher TM, Shen DD, Liberato N, Grant KS, Cernichiari E, et al. (2005) Comparison of blood and brain mercury levels in infant monkeys exposed to methylmercury or vaccines containing Thimerosal. Environ Health Perspect 113: 1015-1021. [Crossref] 
13. Burbacher TM, Charleston LB, Charleston J (2014) A comparative study of Thimerosal in vaccines with methylmercury in a nonhuman primate model. Neurotoxicol Teratol 43: 91-94.

14. Centers for Disease Control and Prevention (CDC) (1999) Thimerosal in vaccines: a joint statement of the American Academy of Pediatrics and the Public Health Service. MMWR Morb Mortal Wkly Rep 48: 563-565. [Crossref]

15. U.S. Food and Drug Administration Protecting and Promoting Your Health. Thimerosal inVaccines.

16. Pichichero ME, Cernichiari E, Lopreiato J, Treanor J (2002) Mercury concentrations and metabolism in infants receiving vaccines containing thiomersal: A descriptive study. Lancet 360: 1737-1741. [Crossref]

17. U S Environmental Protection Agency (1997) Mercury Study Report to Congress. Washington, DC: US Environmental Protection Agency.

18. Hviid A, Stellfeld M, Wohlfahrt J, Melbye M (2003) Association between thimerosalcontaining vaccine and autism. JAMA 290: 1763-1766. [Crossref]

19. American Academy of Pediatrics, United States Public Health Service (1999) Join statement of the American Academy of Pediatrics and United States Public Health Service. Pediatrics 104: 568-569.

20. Paul Y (2005) Preservatives in DPT vaccine. Indian Pediatr 42: 1006-1007. [Crossref]

21. Axelrad DA, Bellinger DC, Ryan LM, Woodruff TJ (2007) Dose-response relationship of prenatal mercury exposure and IQ: an integrative analysis of epidemiologic data. Environ Health Perspect 115: 609-615. [Crossref]

22. National Research Council, Committee on the toxicological effects of methylmercury (2000) Toxicological Effects of Methylmercury. Washington DC: National Academy Press.

23. Young HA, Geier HA, Geier MR (2008) Thiomersal exposure in infant and neurodevelopmental disorders: An assessment of computerized medical records in vaccine safety datalink. J Neurol Sci 271: 110-118. [Crossref]

24. Evans TA, Siedlak SL, Lu L, Fu X, Wang Z, et al. (2008) The autistic phenotype exhibits remarkably localized modification of brain protein by products of free radicalinduced lipid oxidation. AmJ Biochem Biotechnol 4: 61-72.

25. Lopez HE, Prieto JJ (2008) A microscopic study of language-related cortex in autism. Am J Biochem Biotechnol 4: 130-145.

26. Sajdel-Sulkowska EM, Lipinski B, Windom H, Audhya T, McGinnis W (2008) Oxidative stress in autism: elevated cerebellar 3-nitrotyrosine levels. Am J Biochem Biotechnol 4: 73-84.

27. Geier DA, Hooker BS, Kern JK, King PG, Sykes LK, et al. (2013) A two-phase study evaluating the relationship between Thimerosal-containing vaccine administration and the risk for an autism spectrum disorder diagnosis in the United States. Translational Neurodegeneration 2: 25 .

28. Geier DA, Hooker BS, Kern JK, King PG, Sykes LK, et al. (2014) A Dose-Response Relationship between Organic Mercury Exposure from Thimerosal-Containing Vaccines and Neurodevelopmental Disorders. Int J Environ Res Public Health 11: 9156-9170. [Crossref]

29. Geier DA, Kern JK, King PG, Sykes LK, Geier MR (2015) A Case-Control Study Evaluating the Relationship Between Thimerosal-Containing Haemophilus influenzae Type b Vaccine Administration and the Risk for a Pervasive Developmental Disorder Diagnosis in the United States. Biol Trace Elem Res 163: 28-38. [Crossref]

30. Geier DA, Kern JK, Hooker BS, et al. (2016) Thimerosal-Preserved Hepatitis B Vaccine and Hyperkinetic Syndrome of Childhood. Brain Sci 6. [Crossref]

31. Geier DA, Kern JK, Hooker BS, King PG, Sykes LK, et al. (2016) A longitudinal cohort study of the relationship between Thimerosal-containing hepatitis B vaccination and specific delays in development in the United States: Assessment of attributable risk and lifetime care costs. Journal of Epidemiology and Global Health 6: 105-118. [Crossref]

32. Dórea JG, Marques RC, Brandão KG (2009) Neonate exposure to thimerosal mercury from hepatitis B vaccines. Am J Perinatol 26: 523-527. [Crossref]

33. Kern JK, Haley BE, Geier DA, Sykes LK, King PG, et al. (2013) Thimerosal exposure and the role of sulfation chemistry and thiol availability in autism. Int J Environ Res Public Health 10: 3771-3800. [Crossref]

34. Dórea JG (2015) Exposure to mercury and aluminum in early life: developmental vulnerability as a modifying factor in neurologic and immunologic effects. Int $J$ Environ Res Public Health 12: 1295-1313. [Crossref]

35. Institute of Medicine of the National Academies, Immunization safety review committee Board on health promotion and disease prevention (2004) Immunization safety review. Vaccines and Autism. Washington: The National academies Press.

36. Parker SK, Schwartz B, Todd J, Pickering LK (2004) Thimerosal-containing vaccine and autistic spectrum disorder: a critical review of published original data. Pediatrics 114: 793-804. [Crossref]

37. Heron J, Golding J, Team AS (2004) Thiomersal exposure in infants and developmenta disorders: Prospective cohort study in the United Kingdom does not support a causal association. Pediatrics 114: 577-583. [Crossref]

38. World Health Organization (2003) WHO Guidelines on regulatory expectations related to the elimination, reduction or replacement of thiomersal in vaccines: technical report series.

39. Knezevic I, Griffiths E, Reigel F, Dobbelaer R (2004) Thiomersal in vaccines: a regulatory perspective WHO Consultation, Geneva, 15-16 April 2002. Vaccine 22: 1836-1841. [Crossref]

40. Fombonne E, Zakarian R, Bennett A, et al. (2006) Pervasive developmental disorders in Montreal, Quebec, Canada: prevalence and links with immunization. Pediatrics 118: $139-150$

41. Stratton D, Gable A, McCormick MC (2001) Institute of Medicine Immunization Safety Review: Thiomersal-containing Vaccines and Neurodevelopmental Disorders. (eds.), National Academy Press (U.S.), Washington DC.

42. Gundacker C, Pietschnig B, Wittmann KJ, Lischka A, Salzer H, et al. (2002) Lead and mercury in breast milk. Pediatrics 110: 873-878. [Crossref]

43. Clark SJ, Cabana MD, Malik T, Yusuf H, Freed GL (2001) Hepatitis B vaccination practices in hospital newborn nurseries before and after changes in vaccination recommendations. Arch Pediatr Adolesc Med 155: 915-920. [Crossref]

44. Mitkus RJ, King DB, Walderhaug MO, Forshee RA (2014) A comparative pharmacokinetic estimate of mercury in U.S. Infants following yearly exposures to inactivated influenza vaccines containing thimerosal. Risk Anal 34: 735-750.

45. Taylor LE, Swerdfeger AL, Eslick GD (2014) Vaccines are not associated with autism an evidence-based meta-analysis of case-control and cohort studies. Vaccine 32: 3623 3629. [Crossref]

46. Budzyn DM, Majewska R, Kieltyka A (2015) Early exposure to thimerosal-containing vaccines and children's cognitive development. A nine year prospective birth cohor study in Poland. Eur J Pediatr 174: 383-391. [Crossref]

47. Hurley AM, Tadrous M, Miller ES (2010) Thimerosal-containing vaccines and autism: a review of recent epidemiologic studies. J Pediatr Pharmacol Ther 15: 173-181. [Crossref]

48. Folb PI, Bernatowska E, Chen R, Clemens J, Dodoo AN, et al. (2004) A globa perspective on vaccine safety and public health: the Global Advisory Committee on Vaccine Safety. Am J Public Health 94: 1926-1931. [Crossref]

Copyright: (C2016 Roy S. This is an open-access article distributed under the terms of the Creative Commons Attribution License, which permits unrestricted use, distribution, and reproduction in any medium, provided the original author and source are credited. 